\title{
Phonological similarity and orthographic similarity affect probed serial recall of Chinese characters
}

\author{
Yi-Chen Lin • Hsiang-Yu Chen • Yvonne C. Lai • \\ Denise H. Wu
}

Published online: 24 December 2014

(C) Psychonomic Society, Inc. 2014

\begin{abstract}
The previous literature on working memory (WM) has indicated that verbal materials are dominantly retained in phonological representations, whereas other linguistic information (e.g., orthography, semantics) only contributes to verbal WM minimally, if not negligibly. Although accumulating evidence has suggested that multiple linguistic components jointly support verbal WM, the visual/orthographic contribution has rarely been addressed in alphabetic languages, possibly due to the difficulty of dissociating the effects of word forms from the effects of their pronunciations in relatively shallow orthography. In the present study, we examined whether the orthographic representations of Chinese characters support the retention of verbal materials in this language of deep orthography. In Experiments 1a and 2, we independently manipulated the phonological and orthographic similarity of horizontal and vertical characters, respectively, and found that participants' accuracy of probed serial recall was reduced by both similar pronunciations and shared phonetic radicals in the to-be-remembered stimuli. Moreover, Experiment $1 \mathrm{~b}$ showed that only the effect of phonological, but not that of orthographic, similarity was affected by
\end{abstract}

\section{Y.-C. Lin}

Institute of Neuroscience, National Yang-Ming University, Taipei, Taiwan

Y.-C. Lin • H.-Y. Chen • Y. C. Lai • D. H. Wu

Laboratories for Cognitive Neuroscience, National Yang-Ming

University, Taipei, Taiwan

H.-Y. Chen • D. H. Wu ( $₫)$

Institute of Cognitive Neuroscience, National Central University,

No.300, Jhongda Road, Jhongli City, Taoyuan County 32001,

Taiwan

e-mail: denisewu@cc.ncu.edu.tw

Y. C. Lai

Institute of Neuroscience (Academic Psychiatry), Newcastle

University, Newcastle upon Tyne, UK concurrent articulatory suppression. Taken together, the present results indicate the indispensable contribution of orthographic representations to verbal WM of Chinese characters, and suggest that the linguistic characteristics of a specific language not only determine long-term linguistic-processing mechanisms, but also delineate the organization of verbal WM for that language.

Keywords Short-term memory $\cdot$ Working memory $\cdot$ Memory models $\cdot$ Lexical processing $\cdot$ Word recognition

Working memory (WM) is usually conceptualized as a system with a limited capacity to maintain and manipulate information for a short period of time. The WM model with multiple components (Baddeley, 1986, 2000; Baddeley \& Hitch, 1974) is one of the most prominent accounts to describe the mechanisms of WM. According to this model, verbal information is retained mainly, if not exclusively, in phonological representations. This claim is supported by the robust effects of phonological similarity (i.e., phonologically dissimilar words are remembered better than phonologically similar ones; Baddeley, 1966b; Conrad \& Hull, 1964), word length (i.e., words with shorter spoken durations are remembered better than those with longer spoken durations; Baddeley, Thomson, \& Buchanan, 1975), and articulatory suppression (i.e., concurrent articulation of irrelevant sounds abolishes the word length effect in immediate serial-recall tasks in the visual, but not in the auditory, modality; Baddeley, Lewis, \& Vallar, 1984; Baddeley et al., 1975; Murray, 1968). In contrast, the semantic similarity effect is more significant in affecting the memory performance in subsequent memory tests than in immediate recall (Baddeley, 1966a, 1966b). In the early study conducted by Baddeley (1966b), it was also found that when the pronunciations of spoken words in a list were all different, the memory accuracy of words with distinct spellings (e.g., 
friend, sleigh, and board) was equivalent to that of words with similar spellings (e.g., rough, cough, and through). Such results showed that the manipulation of orthographic similarity did not result in different performance in participants' immediate recall.

Despite the early findings of the lack of effects of word forms and meanings on verbal WM, a growing body of evidence has suggested that phonological representation and covert rehearsal may not be the only mechanisms supporting the temporary maintenance of verbal information. Several lexical and semantic factors have been shown to affect WM performance. For example, words are recalled better than nonwords (Besner \& Davelaar, 1982; Brener, 1940; Crowder, 1976; Hulme, Maughan, \& Brown, 1991), high-frequency words are recalled better than low-frequency ones (Hulme et al., 1997; Roodenrys, Lethbridge, Hinton, Nimmo, \& Hulme, 2002), and concrete words are recalled better than abstract ones (Caza \& Belleville, 1999; Romani, McAlpine, \& Martin, 2008; Walker \& Hulme, 1999). In addition, neuropsychological reports (Freedman \& Martin, 2001; Martin, Shelton, \& Yaffee, 1994) have demonstrated selective deficits of retaining the sound and meaning of verbal materials in WM in different brain-damaged patients. Neuroimaging studies have also revealed dissociable networks underlying phonological and semantic retention in probed recognition (Martin, Wu, Freedman, Jackson, \& Lesch, 2003) and in delayed rhyme/synonym judgments (Shivde \& ThompsonSchill, 2004). Thus, the accumulating findings support the multiple-capacity account (Martin \& Romani, 1994; Martin et al., 1994), which postulates that verbal WM is subserved by phonological, semantic, and even syntactic processing (Caza \& Belleville, 1999).

The contribution of orthography to verbal WM has been largely ignored in the literature, because early attempts to investigate the influence of word forms on the retention of verbal materials in alphabetic languages have often resulted in null effects (e.g., Baddeley, 1966b). One possible explanation was that the mapping between orthography and phonology of alphabetic languages is rule-based and relatively "shallow" (Frost, Katz, \& Bentin, 1987), rendering the information provided by phonology and orthography partially or even fully redundant. Therefore, phonological information alone is sufficiently distinct to support verbal WM in most cases. Consistent with such reasoning, the WM theory (Baddeley, 1986; Baddeley \& Hitch, 1974) hypothesizes that verbal materials are exclusively maintained in the phonological loop under typical circumstances, whereas the other slave system of the WM model-namely, the visuo-spatial sketchpad (Logie, 1986, 1995; Logie \& Marchetti, 1991) — can be relied on when the sounds of verbal materials was not available, as in some brain-damaged patients (e.g., Warrington \& Shallice, 1972), or when the phonological representation does not provide sufficient information for differentiation between memory's contents.
Supporting the hypothesis of the WM model, Logie, Della Sala, Wynn, and Baddeley (2000) reported that immediate serial recall of words with different spellings (e.g., GUY, SIGH, and LIE) was better than that of words with similar spellings (e.g., CRY, DRY, and TRY). Similarly, immediate serial recall of both the identity and case of individual letters that were presented in either upper- or lowercase was better for letters whose upper- and lowercase variants were visually distinct (e.g., Hh, Rr, and Qq) than for letters whose upperand lowercase variants were visually identical except for size (e.g., $\mathrm{Ww}, \mathrm{Cc}$, and $\mathrm{Kk}$ ). These effects were observed regardless of articulatory suppression, suggesting that they did not arise from covert rehearsal of the stimuli. Therefore, the authors concluded that the visual WM system (i.e., the visuo-spatial sketchpad) was also available to support the retention of verbal materials. However, in addition to having visually similar upper- and lowercase variants, the letter name of $\mathrm{W}$ is also phonologically longer than those of letters with distinct upper- and lowercase variants, which might have resulted in worse memory performance especially under the condition without articulatory suppression. After removing this potential confound, Fürstenberg, Rummer, and Schweppe (2013) recently demonstrated that the effect of visual similarity among to-be-remembered letters was only found under articulatory suppression, but was not detected without articulatory suppression. On the basis of these results, it was argued that visually presented verbal materials are mainly retained by the linguistic-specific (i.e., phonological) mechanism, whereas the involvement of the visuo-spatial sketchpad is not necessary.

To determine whether the similarity of word forms affects WM performance in a deep-orthography language, which allows for independent manipulations of the phonological and visual similarity of to-be-remembered words, Saito, Logie, Morita, and Law (2008) investigated the written serial recall of Japanese kanji. In addition to demonstrating the classic phonological similarity effect (PSE) for memorizing written kanji in native Japanese readers, they found that visually dissimilar characters were recalled better than visually similar ones, regardless of the phonological similarity of the stimuli, especially when considering the accuracy of order information. Furthermore, articulatory suppression only abolished the PSE, but not the visual similarity effect (VSE). On the basis of these results, the researchers concluded that both phonological and visual codes are involved to support the WM of Japanese kanji.

Like Japanese kanji, Chinese characters also form a logographic writing system that is orthographically deeper than alphabetic languages. Unlike Japanese kanji, on the other hand, the radicals within Chinese characters not only appear as visual patterns of strokes, but also provide phonological and semantic information for the whole character, which aids reading (Ding, Peng, \& Taft, 2004; Feldman \& Siok, 1997, 
1999; Hung, Hung, Tzeng, \& Wu, 2014; Lee et al., 2004; Lee, Tsai, Su, Tzeng, \& Hung, 2005; Taft \& Zhu, 1997; Taft, Zhu, \& Peng, 1999; Tsai, Lee, Tzeng, Hung, \& Yen, 2004). Although there is no mapping between subcharacter stroke patterns and subword phonemes in Chinese, according to the Academia Sinica Balanced Corpus (Huang \& Chen, 1998), the approximately 700 phonetic radicals and 200 semantic radicals of Chinese provide coarse cues as to the pronunciation and meaning, respectively, of a character. For example, the Chinese character 楓 "maple" is pronounced/feng $1 /$, which is homophonic to the phonetic radical (風/feng1/, meaning "wind") on the right side of the character. The semantic radical on the left side of the character (木 $/ \mathrm{mu} 4 /$, meaning "wood") indicates the semantic category of the character meaning. The majority ( $>0 \%)$ of Chinese characters (i.e., phonograms) have a phonetic radical, which provides semi-useful phonological information regarding the pronunciation of the whole character. Specifically, $47 \%$ of common Chinese characters have a pronunciation (ignoring tone) identical to that of their phonetic radical, and $34 \%$ of characters have the same pronunciation as their orthographic neighbors that share the same phonetic radical (reviewed by Hsiao \& Shillcock, 2006). Although the phonetic radical does not always provide reliable cues to the pronunciation of a Chinese character, it has been consistently reported that Chinese reading involves sublexical processing of this functional unit.

Given that there are abundant homophones among Chinese characters, it does not seem likely that verbal WM of Chinese relies only on the highly ambiguous phonological representation. Previous studies with alphabetic materials have demonstrated that short-term maintenance of verbal information might rely on the representations corresponding to long-term linguistic knowledge (e.g., semantics) in addition to phonology (Acheson, Postle, \& MacDonald, 2010; Freedman \& Martin, 2001; Hulme et al., 1997; Monnier \& Syssau, 2008; Shivde \& Anderson, 2011), which implies close correspondences between the representations of long-term memory (LTM) and WM. Following this reasoning, given that the phonetic radicals of Chinese orthography are linguistically informative and contribute to character recognition (e.g., Hung et al., 2014), it seems plausible that verbal WM of written Chinese characters would take advantage of both the phonological and word-form information provided by the phonetic radicals of to-be-remembered materials.

Few studies have examined the effect of the word forms of Chinese characters on verbal WM. Similar to the findings from alphabetic languages, Mou and Anderson (1981) found both PSE and VSE in immediate recall of Chinese characters, though VSE was only observed when the characters were phonologically similar. However, all of the characters in the visually similar condition shared the same left (usually semantic) radicals. Therefore, the manipulation of visual similarity might be confounded with similarity of the character meanings. Hue and Erickson (1988) also demonstrated that visual complexity (defined by stroke numbers) of Chinese characters only affected WM of characters with low, but not with middle to high, frequency, suggesting that only the retention of unfamiliar Chinese characters relies on visual codes. Likewise, a secondary matrix-matching task during the retention period only affected memory performance for unfamiliar but not for familiar Chinese characters, whereas the opposite pattern was observed under the influence of a secondary homophonematching task. These findings are parallel with those from alphabetic languages in showing that the visual effect of to-beremembered materials is only detected when phonological information is not readily available. It also implies that the retention of linguistic materials in a deep orthography can still be accounted for by the WM model (Baddeley, 1986), which argues that verbal retention relies solely on phonology whenever it is both available and sufficient for differentiating the memory items. However, given the significant contributions of Chinese phonetic radicals to character recognition (e.g., Lee et al., 2005) and the close relationship between long-term and short-term verbal representations (Martin \& Romani, 1994; Martin et al., 1994), we suspect that the orthographic representation of phonetic radicals would have an effect independent of phonology on the WM of Chinese characters.

Although Saito et al. (2008) has already shown that the visual code, together with the phonological code, is relied on to support the retention of Japanese kanji, the VSE in immediate recall might result from the same mechanism that gives rise to the VSE observed in the retention of nameable pictures, even when the to-be-remembered stimuli were phonologically distinct (Hitch, Woodin, \& Baker, 1989; Poirier, Saint-Aubin, Musselwhite, Mohanadas, \& Mahammed, 2007). Therefore, it is worth examining whether the functional units in a different logographic system-namely, the phonetic radicals of Chinese characters - contribute to verbal WM through their orthographic and phonological representations. To address this question, in the present study we systematically examined the effects of pronunciation and word-form similarity among a close set of Chinese characters in the probed serial-recall paradigm, in which order rather than item information is emphasized. Relative to previous research, the present stimuli and task minimized the influence of LTM on performance in a WM task and avoided the potential confounds of memory decay and response interference during the retrieval periods. Specifically, in both Experiments 1 and 2, Chinese characters with identical or rhymed pronunciations were selected to form phonologically similar (Ps) lists that would contrast with phonologically dissimilar (Pd) lists comprising Chinese characters with distinct pronunciations. As for the manipulation of orthographic similarity, horizontal characters with shared phonetic radicals on the right side were selected to form orthographically similar (Os) lists that would contrast with 
orthographically dissimilar (Od) lists, presented without articulatory suppression in Experiment 1a, and with articulatory suppression in Experiment 1b. In Experiment 2, all characters selected had a vertical structure, so that the characters in the Os lists shared phonetic radicals at the top or bottom of the characters, whereas those in the Od lists did not.

\section{Experiment 1}

We orthogonally manipulated pronunciation and word-form similarity among Chinese characters to determine the involvement of phonological and orthographic representations in verbal WM without (Exp. 1a) and with (Exp. 1b) concurrent articulatory suppression. To minimize the contribution from LTM, a closed set of Chinese characters were selected, since the previous research has shown that memory performance with an open set of stimuli in the immediate serial-recall task might be affected by representations in both WM and LTM (e.g., Monnier \& Syssau, 2008). Furthermore, to control for the potential influence of character structure and its interaction with the functions of radicals within characters, all of the characters selected in Experiment 1 were horizontal compound phonograms with their semantic and phonetic radicals on the left and right sides, respectively, as is true of the majority of common characters in modern Chinese vocabulary.

\section{Method}

\section{Participants}

Thirty-two undergraduate and graduate students (16 in Exp. 1a: eight females, eight males, 19 to 27 years of age; and another 16 in Exp. 1b: eight females, eight males, 20 to 27 years of age) from National Central University, Taiwan, participated in this experiment. All of them were fluent, native Chinese speakers and readers, were right-handed, and had normal or corrected-to-normal vision. They gave their informed consents to participate in the experiment.

\section{Materials and design}

The experiment had three within-participant variables: similar (Ps) or dissimilar (Pd) phonology among list characters, similar (Os) or dissimilar (Od) orthography among list characters, and serial position of the probed character in the memory list (from 1 to 8). Eight Chinese characters with a horizontal structure were selected for each of the four stimulus conditions (see Appendix A).

For the manipulation of phonological similarity, in the two $\mathrm{Pd}$ conditions (PdOd and PdOs), the eight characters in the same list did not share either a sound or a rhyme. In contrast, in the two Ps conditions ( $\mathrm{PsOd}$ and PsOs), the eight characters in the same list included four pairs, two of which were homophones and the other two of which included characters with the same rhyme. For the manipulation of orthographic similarity, in the two Od conditions (PdOd and PsOd), the eight characters in the same list did not share any radical. In the two Os conditions (PdOs and PsOs), the lists included four pairs of characters that shared the same phonetic radical on the right side of the characters. In addition, to prevent participants from relying on the left (semantic) radical to retain the stimuli when encountering a list of characters with shared radicals on the right side, the characters in the PdOs and PsOs conditions shared three left radicals within a list, so that the left radical alone did not provide unique and sufficient information as to the identity of the list characters (see Appendix A). Across the four conditions, the mean character frequencies and the mean numbers of strokes of the eight characters in a list were matched, $F_{\mathrm{s}}(3,28)<1$ (Table 1).

The manipulation of phonological similarity was verified by subjective ratings, ${ }^{1}$ while the manipulation of orthographic similarity was verified by both subjective ratings and an objective index. ${ }^{2}$ The subjective ratings confirmed the validity of the similarity manipulations of phonology (Pd: 1.97, Ps: 2.33) $\left[F(1,17)=52.954, M S E=.045, p<.001, \eta^{2}=.095\right]$ and orthography (Od: 1.81 , Os: 2.94$)[F(1,17)=21.691, M S E=$ $\left..080, p<.001, \eta^{2}=.072\right]$. The objective visual similarity was indeed higher in the Os than in the Od lists $[F(1,28)=51.594$, $\left.M S E=.0009, p<.001, \eta^{2}=.648\right]$, whereas visual similarity

\footnotetext{
${ }^{1}$ Subjective ratings of the phonological and visual similarity of the materials in the four lists were obtained from 18 undergraduate and graduate students (ten females, eight males; 20-29 years of age) from National Central University, Taiwan, all of whom were right-handed, native and fluent Chinese readers and speakers. They did not participate in any of the memory experiments in the present study. Each character was paired with any of the other characters within the same list, which resulted in 56 trials for each stimulus condition. The two paired characters were presented sequentially with a presentation duration of $800 \mathrm{~ms}$ and an interstimulus interval of $200 \mathrm{~ms}$. Participants were required to judge the phonological and visual similarity of the paired characters in two separate trials on a 6-point scale, with 1 representing extremely dissimilar and 6 representing extremely similar. The order of the judgments of phonological and visual similarity of the paired characters was counterbalanced across participants.

${ }^{2}$ The degree of orthographic similarity among the characters within a list was objectively determined by counting the pixels that were commonly occupied by the strokes of a pair of characters within a square space that contained individual characters. Specifically, we first calculated the number of pixels that were occupied by the strokes of each character. According to this index, the visual complexities of the list characters did not differ among the four stimulus conditions $[F(3,28)<1$, Table 1]. On the basis of this visual complexity of the individual characters, the degree of orthographic similarity between any two characters from the same list was obtained by calculating the overlapping pixels occupied by the strokes of the two characters. The orthographic similarity of each condition was the mean of these indices from the 28 pairs of all possible combinations between the eight characters within a condition.
} 
Table 1 Characteristics of the materials in Experiment 1

\begin{tabular}{|c|c|c|c|c|}
\hline & PdOd & $\mathrm{PdOs}$ & PsOd & PsOs \\
\hline Mean character frequency & 204 & 176 & 235 & 191 \\
\hline Mean stroke number & 11 & 11 & 10 & 11 \\
\hline$\%$ of pixel occupied by the strokes & 11.84 & 11.60 & 12.46 & 11.73 \\
\hline Mean normalized $\%$ of pixel that two characters overlap & 24.32 & 34.82 & 26.20 & 31.37 \\
\hline Mean visual similarity rating $(n=18)$ & 1.85 & 3.03 & 1.77 & 2.85 \\
\hline Mean phonological similarity rating $(n=18)$ & 1.78 & 2.16 & 2.21 & 2.46 \\
\hline
\end{tabular}

For the subjective rating, 1 represents extremely dissimilar, and 6 represents extremely similar

did not differ between the Ps and Pd lists $[F(1,28)<1]$ (Table 1).

In the probed serial-recall paradigm, each of the eight characters in a condition was sequentially presented to participants in a trial. At the end of a trial, one character that had previously appeared in the list was selected as the probed character. Each character was selected as the probe at each serial position once, which resulted in 64 trials for each condition, and 256 trials in total. To limit the testing duration for each participant to be within $1 \mathrm{~h}$, the complete set of 256 trials was evenly divided into two subsets (128 trials), which had 32 trials in each condition. Within each subset, each character within a list was probed four times, and each serial position was probed 16 times, with four times in each condition. The assignment of the subsets to participants was counterbalanced across participants. For each participant, the 128 total trials were divided into eight blocks. Each block contained 16 trials, with four trials in each condition. The presentation order of the four types of experimental conditions was blockrandomized within a block.

\section{Procedure}

Experiment $1 a$ Each participant was tested individually in a quiet room with dim light. In order to make sure that the participants could correctly recognize and pronounce the 32 characters that were employed in the experiment, they were asked to name each of the stimuli aloud before the experiment started. After the naming procedure, all participants underwent eight practicing trials, which were identical to the experimental trials, with two trials in each condition. Participants had to correctly answer at least three practice trials before they received the experimental trials. The participants who failed to pass this criterion received the practice session again until they had met the criterion. No participants required more than two runs of practice.

An experimental trial began with a fixation "+" at the center of the screen for $800 \mathrm{~ms}$. Following a blank of $200 \mathrm{~ms}$ from the end of fixation, eight characters within the same condition were shown sequentially. Each stimulus was presented for $800 \mathrm{~ms}$, with a $200-\mathrm{ms}$ interstimulus interval. Participants were asked to silently remember the order of the eight characters. Following the character presentation, a probed character from the previous list was presented at the center of the screen, and the Arabic digits 1 to 8 were listed below the probed character simultaneously. The participants were instructed to indicate the serial order of the probed character in the previous list by pressing the corresponding number key on the keyboard. No time limit was imposed for the manual response. After performing the serial recall, participants pressed the space bar to initiate the next trial. Feedback on their response accuracy was only provided to participants in the practice session, but not in the formal experiment.

Experiment $1 b$ The procedure was similar to that of Experiment 1a, except that participants were required to say "the, the, the ..." at a pace of two words per second from the presentation of the fixation till they made a manual probedrecall response in each trial. Although "th" is not one of the phonemes appearing in the Chinese language, "the" was a highly familiar English word for these participants, who all had had English classes since high school.

Results

Experiment $1 a$ The accuracy of the probed serial recall in each trial was recorded and analyzed. The mean accuracies of the four stimulus conditions at different serial positions are shown in Fig. 1a. A 2 (phonological similarity: dissimilar vs. similar) $\times 2$ (orthographic similarity: dissimilar vs. similar $) \times 8$ (serial position of the probed character: from 1 to 8 ) repeated measures analysis of variance (ANOVA) was performed on the accuracy of the participants' responses. The results revealed a significant PSE $[F(1,15)=61.892, M S E=.05, p<$ $\left..001, \eta^{2}=.129\right]$, indicating that phonologically dissimilar characters (memory accuracy $=.89$ ) were remembered better than phonologically similar ones (memory accuracy $=.74$ ). The effect of orthographic similarity (OSE) was also highly significant $\left[F(1,15)=19.910, M S E=.004, p<.001, \eta^{2}=\right.$ .037], showing that the memory for characters without any shared radicals (mean $=.85$ ) was better than the memory for characters with shared phonetic radicals (mean $=.77$ ). The manipulation of orthographic similarity did not interact with any other effects $(F \mathbf{s}<1)$, which indicated that the 
a

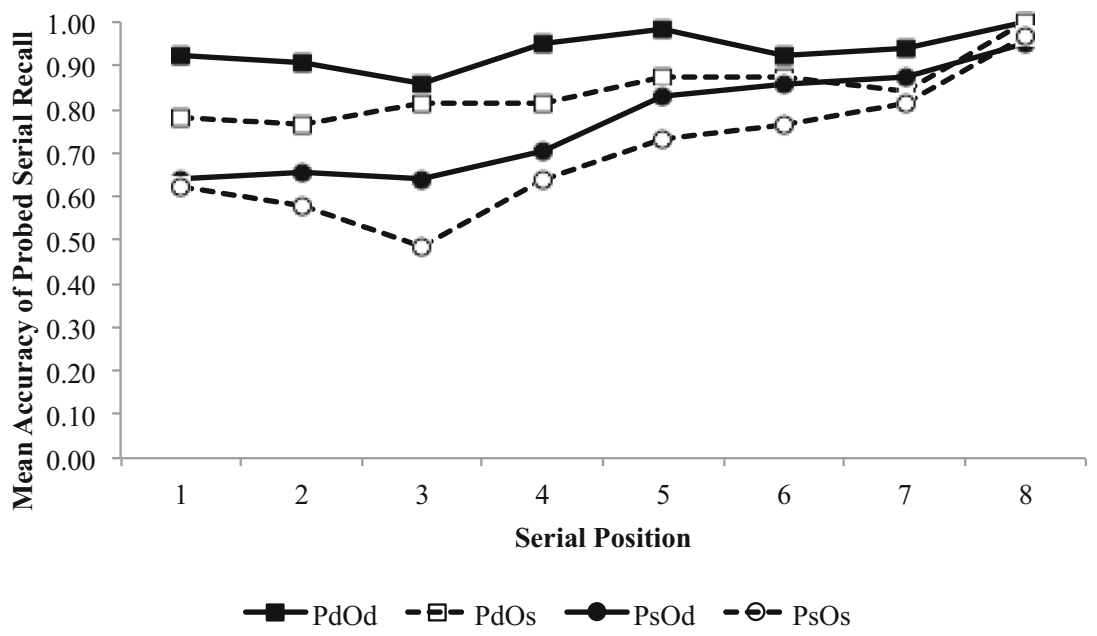

b

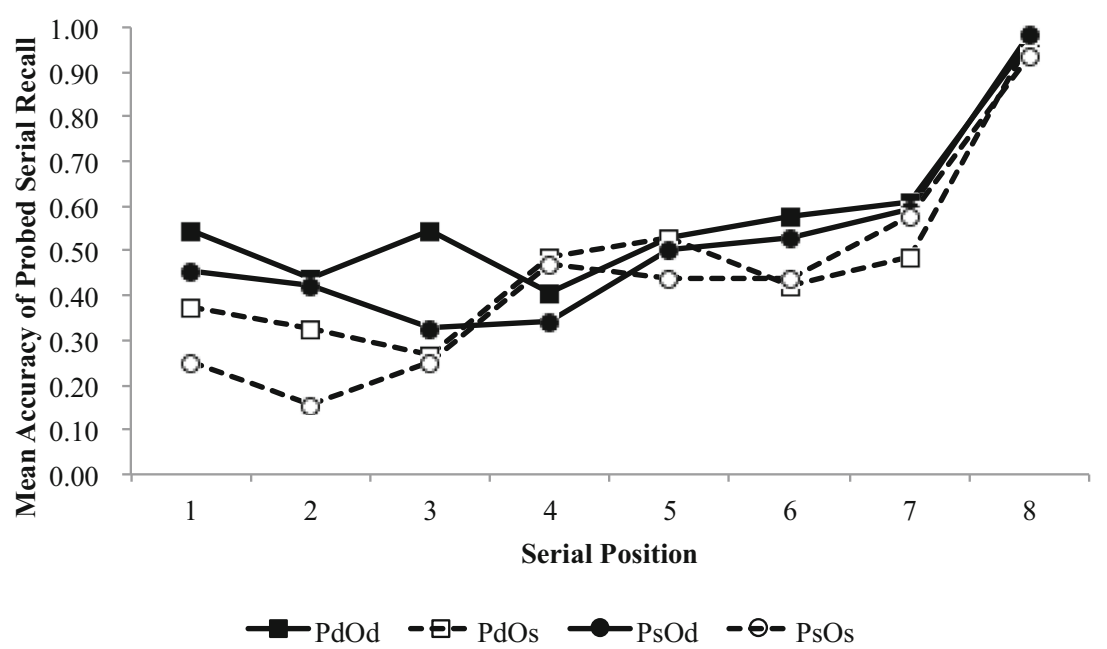

Fig. 1 (a) Mean accuracies of probed serial recall across serial positions without concurrent articulatory suppression, in Experiment 1a. (b) Mean accuracies of probed serial recall across serial positions with concurrent articulatory suppression, in Experiment $1 \mathrm{~b}$

orthographic similarity of verbal material affected WM performance regardless of the usefulness of the phonological information or the serial position of the probed character.

Consistent with the WM literature, the ANOVA result also revealed a significant effect of serial position $[F(7,105)=$ 8.797, MSE $\left.=.064, p<.001, \eta^{2}=.159\right]$, showing strong primary and recency effects. We observed a significant interaction between phonological similarity and serial position $\left[F(7,105)=4.305, M S E=.029, p<.001, \eta^{2}=.041\right]$. Posthoc comparisons [Bonferroni method, $p(8)=.0018$ ] indicated that the PSE was significant from the second to the fifth serial positions ( $p \mathrm{~s}<.0013)$, but not at the first or between the sixth and eighth serial positions, which was similar to the pattern in previous findings (e.g., Baddeley et al., 1975).

Experiment $1 b$ The mean accuracies of the four stimulus conditions at different serial positions are shown in Fig. 1b. An ANOVA conducted like that in Experiment 1a showed that the
PSE was weak but still significant (memory accuracy: $\mathrm{Pd}=.53$, $\mathrm{Ps}=.48)\left[F(1,15)=6.259, M S E=.053, p=.024, \eta^{2}=.009\right]$. On the other hand, the OSE was stable and highly significant (memory accuracy: $\mathrm{Od}=.55 ; \mathrm{Os}=.46)[F(1,15)=21.108, M S E=$ $\left..047, p<.001, \eta^{2}=.028\right]$, even under articulatory suppression. The ANOVA results again revealed a significant effect of serial position $\left[F(7,105)=24.108, M S E=.108, p<.001, \eta^{2}=.344\right]$, with an especially strong recency effect at the eighth serial position (see Fig. 1b). Consistent with the findings of Experiment 1a, the manipulation of orthographic similarity did not interact with the PSE $[F(1,15)<1]$. The interaction between orthographic similarity and serial position reached significance $\left[F(7,105)=3.379, M S E=.050, p=.003, \eta^{2}=.033\right]$, reflecting that the OSE was most pronounced at the second serial position $(p=.0012)$. No other effects were significant $(F \mathrm{~s}>.361)$.

Direct comparison of experiments $1 a$ and $1 b$ In order to elucidate how articulatory suppression modulated the magnitudes 
of the PSE and OSE across serial positions, a 2 (articulatory suppression: with vs. without) $\times 2$ (phonological similarity: dissimilar vs. similar) $\times 2$ (orthographic similarity: dissimilar vs. similar) $\times 8$ (serial position of the probed character: from 1 to 8) mixed ANOVA was performed on the accuracies of the participants' responses in Experiments 1a and 1b. The results showed a significant main effect of articulatory suppression $\left[F(1,30)=101.249, M S E=.24, p<.001, \eta^{2}=.305\right]$, indicating that memory performance was much better without concurrent articulatory suppression $($ mean $=.81)$ than with it $($ mean $=.50)$. Also, the ANOVA results revealed in significant main effects of phonological similarity $[F(1,30)=52.972$, $\left.M S E=.051, p<.001, \eta^{2}=.047\right]$, orthographic similarity [ $F(1$, $\left.30)=40.996, M S E=.044, p<.001, \eta^{2}=.031\right]$, and serial position $\left[F(7,210)=31.411, M S E=.086, p<.001, \eta^{2}=.254\right]$.

Critical to the direct comparison between Experiments 1a and $1 \mathrm{~b}$, which involved the variable of articulatory suppression, the ANOVA revealed a significant interaction between this variable and phonological similarity $[F(1,30)=13.622, M S E=.051, p=$ $.001, \eta^{2}=.012$; see Fig. 2a]. Although the PSEs in both Experiments $1 \mathrm{a}$ and $1 \mathrm{~b}$ were significant, as indicated above, the significant interaction further showed that concurrent articulatory suppression greatly reduced the effect of phonological similarity. On the other hand, the interaction between articulatory suppression and orthographic similarity was not significant $[F(1,30)<$ 1], indicating that the significant OSEs detected in both Experiments $1 \mathrm{a}$ and $1 \mathrm{~b}$ were robust, regardless of articulatory suppression, and their magnitudes were not modulated by concurrent phonological interference. The interaction between articulatory suppression and serial position was also significant $[F(7$, $\left.210)=5.444, M S E=.086, p<.001, \eta^{2}=.056\right]$. Post-hoc comparisons [Bonferroni method, $p(8)=.0018$ ] revealed that the effect of articulatory suppression reduced the recall accuracies from the first to the seventh serial positions $(p s<.0001)$, but not at the eighth serial position $(p=.361)$.

The three-way interactions of the ANOVA involving the variables of articulatory suppression and serial position also provided evidence for the different effects of phonological and orthographic similarity on recall accuracy. Specifically, the interaction among phonological similarity, articulatory suppression, and serial position was not significant $[F(7,210)<$ 1], suggesting that the PSE was constantly reduced by articulatory suppression across serial positions (Fig. 2a). In contrast, the interaction among orthographic similarity, articulatory suppression, and serial position was marginally significant $\left[F(7,210)=1.997, M S E=.042, p=.057, \eta^{2}=\right.$ .011]. Post-hoc comparisons revealed that the OSE was not affected by articulatory suppression at most of the serial positions $(p s>.167)$, except that the OSE was greater without than with articulatory suppression only at the fourth serial position $(p=.026)$ (Fig. 2b). No other interaction that involved articulatory suppression was significant $(p \mathrm{~s}>.201)$.

\section{Discussion}

The results in Experiments $1 \mathrm{a}$ and $1 \mathrm{~b}$ demonstrated the classic effects of phonological similarity (Baddeley, 1966b; Murray, 1968) and articulatory suppression (Murray, 1968) in the probed serial-recall task. In addition, the present results also revealed a significant OSE resulting from the shared radicals among to-be-remembered Chinese characters, even when the stimuli were phonologically distinct. These findings were consistent with those of Saito et al. (2008) in showing a clear and stable OSE across serial positions, and that only the PSE but not the OSE was interfered with by concurrent articulatory suppression. The results provided strong evidence for the involvement of sublexical units of Chinese phonograms in verbal WM. Memory confusion, which reduces the accuracy of probed serial recall, was presumably attributed to the similarity among the phonetic radicals. Nevertheless, due to the fact that the list characters in the orthographically similar conditions also shared some semantic radicals, we cannot rule out the possibility that the similarity among the semantic radicals might also have resulted in memory confusion. The present observation of the OSE arising from shared radicals implies that the important functional units of Chinese characters in LTM also support the short-term retention of Chinese characters, though further research will be needed to verify the contributions from phonetic or semantic radicals.

The findings from Chinese horizontal phonograms suggest that both phonological and orthographic representations independently contribute to the verbal WM of materials in this deep-orthography language. In Experiment 2, we aimed to examine the generalizability of the OSE in WM performance for Chinese characters with a vertical structure. Because some psycholinguistic characteristics (e.g., the consistency of phonetic radicals) of horizontal and vertical characters might be different, comparison of the results of Experiments 1 and 2 would shed light on whether the OSE is sensitive to these psycholinguistic factors.

\section{Experiment 2}

Experiment 1 demonstrated a clear and robust OSE, which was independent of the PSE, on verbal WM for horizontal Chinese characters with shared radicals. Furthermore, the OSE was detected even when the phonological information of the list items was sufficient for accurate memory performance, and even under articulatory suppression. In Experiment 2, Chinese characters with a vertical structure, in which the shared phonetic radicals might be at the upper or lower part of a character, were employed to investigate the 

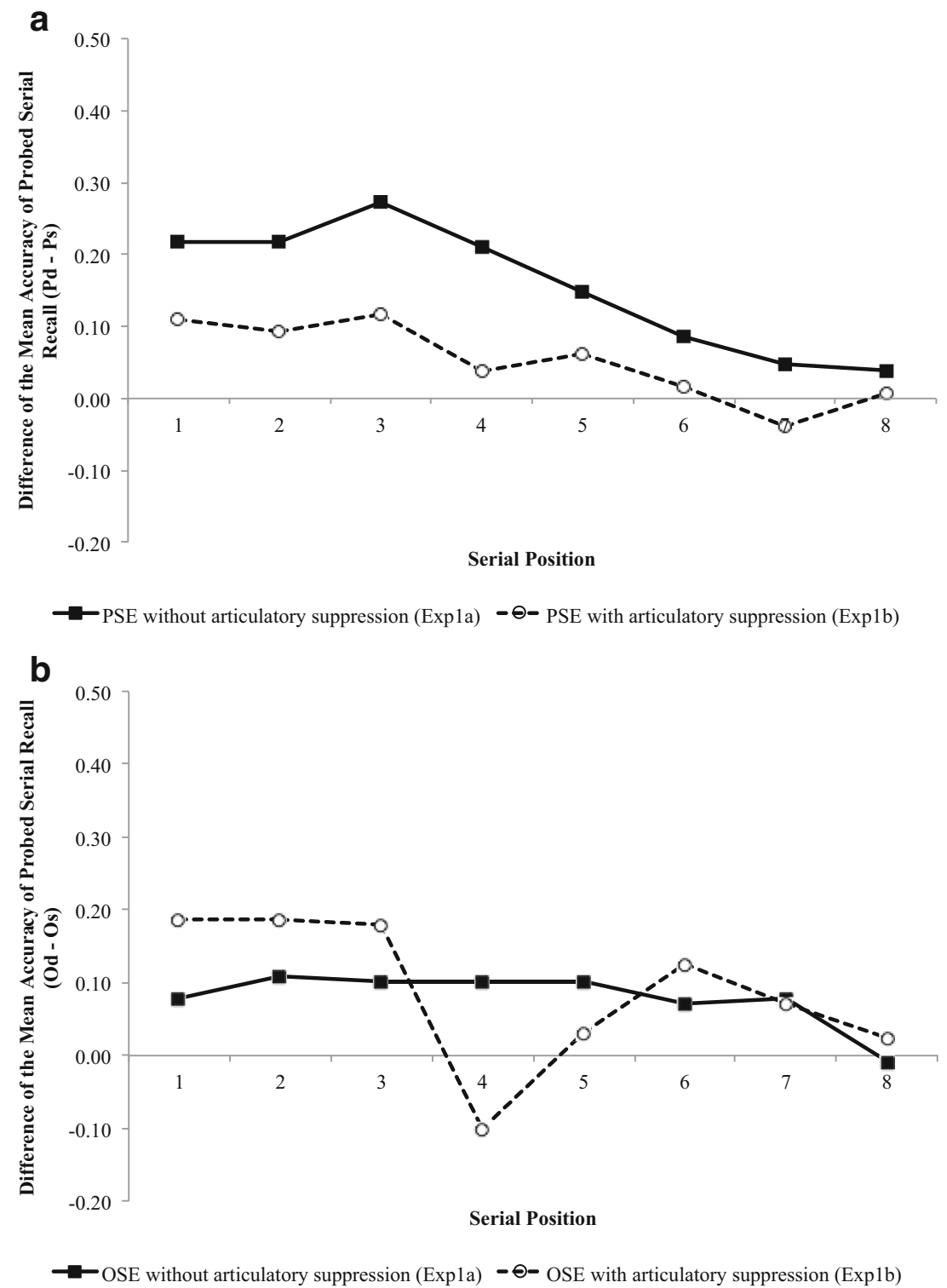

Fig. 2 (a) Effects of phonological similarity without (Exp. 1a) and with (Exp. 1b) articulatory suppression across serial positions. (b) Effects of orthographic similarity without (Exp. 1a) and with (Exp. 1b) articulatory suppression across serial positions

effects of phonological and orthographic similarity on probed serial recall.

\section{Method}

\section{Participants}

Sixteen undergraduate and graduate students (eight females, eight males; 19 to 27 years of age) from National Central University, Taiwan, participated in this experiment. All of them were fluent, native Chinese speakers and readers, were right-handed, and had normal or corrected-to-normal vision. They gave their informed consents to participate in the experiment. None of them had participated in Experiment 1.

\section{Materials and design}

The overall design was identical to that of Experiment 1a, except that all of the characters selected in Experiment $2 \mathrm{had}$ a vertical structure. For the manipulation of phonological similarity, in the two Pd conditions (PdOd and PdOs), the eight characters in the same list did not share either a sound or a rhyme. In contrast, in the two Ps conditions (PsOd and PsOs), the eight characters in the same list included four homophone pairs, except for one pair that differed in tone. For the manipulation of orthographic similarity, in the two Od conditions 
(PdOd and PsOd), the eight characters in the same list did not share any phonetic radical, except that two nonhomophonic characters - namely, 愚/yu2/ and 慈/ci2/—in the PsOd condition shared the same semantic radical 心 /xin1/, meaning "heart," at the bottom of the characters. In contrast with the Od conditions, the stimuli of the two Os conditions (PdOs and PsOs) included four pairs of characters that shared the same phonetic radical, with two shared radicals on top of the characters, and the other two shared radicals at the bottom of the characters. Besides, to prevent participants from relying on the unique semantic radicals of individual characters to remember the list sequence when encountering characters with shared phonetic radicals, two characters (i.e., 熱/dian4/ and壘 /lei3/) in the PdOs condition shared the semantic radical 土/tu3/, meaning "dirt," at the bottoms of the characters, whereas four characters (i.e., 藍/lan $2 /$, 萃 /cui4/, 幕 /mu4/, and慕 /mu4/) in the PsOs condition shared the semantic radical */cao3/, meaning "grass," at the tops of the characters (see Appendix B). Across the four conditions, the mean character frequencies and the mean numbers of strokes were matched $\left[F_{\mathrm{s}}(3,28)<1\right]$. The composition of the testing trials was the same as in Experiment 1.

The manipulation of phonological and orthographic similarity was verified by the same subjective and objective indices via the same procedures as in Experiment 1. ${ }^{3}$ The subjective ratings again confirmed the validity of the similarity manipulations of phonology (Pd: 1.77, Ps: 2.52) $[F(1,16)=430.339, M S E=.022$, $\left.p<.001, \eta^{2}=.402\right]$ and orthography (Od: 1.94, Os: 2.43) $[F(1$, $\left.16)=172.582, M S E=.024, p<.001, \eta^{2}=.170\right]$. As for the objective index of visual similarity, although the visual complexities of the list characters did not differ across the four stimulus conditions $\left[F(3,28)=1, M S E=.0003, p=.39, \eta^{2}=.1\right]$, visual similarity was indeed higher in the Os than in the Od lists $[F(1$, 28) $\left.=10.10, M S E=.0007, p=.004, \eta^{2}=.266\right]$, whereas it did not differ between the Ps and Pd lists $[F(1,28)<1]$ (Table 2).

\section{Procedure}

The procedure was identical to that of Experiment 1a.

\section{Results}

The mean recall accuracies of the four stimulus conditions at different serial positions are shown in Fig. 3. A 2 (phonological similarity: dissimilar vs. similar) $\times 2$ (orthographic similarity: dissimilar vs. similar $) \times 8$ (serial position of the probed character:

\footnotetext{
${ }^{3}$ Subjective ratings of the phonological and visual similarity of the materials in the four lists were obtained from 17 undergraduate and graduate students (nine females, eight males; 20-30 years of age) from National Central University, Taiwan, all of whom were right-handed native and fluent Chinese speakers and readers. They did not participate in rating the stimuli of Experiment 1 or in any of the memory experiments in the present study.
}

from 1 to 8 ) repeated measures ANOVA was performed on the accuracies of the participants' responses. The ANOVA results revealed a significant PSE (memory accuracy: $\mathrm{Pd}=.87, \mathrm{Ps}=$ .62) $\left[F(1,15)=188.770, M S E=.042, p<.001, \eta^{2}=.229\right]$, which was consistent with the findings of Experiment 1 and the previous literature. Because the interaction between phonological similarity and serial position was significant $[F(7,105)=$ 4.231, MSE $\left.=.049, p<.001, \eta^{2}=.052\right]$, post-hoc comparisons of the PSE at individual serial positions [Bonferroni method, $p(8)=.0018]$ were conducted. The results showed that the PSE was significant at the second, third, and between the fifth and seventh serial positions $(p \mathrm{~s}<.0002)$, but not at the first, fourth, or eighth serial positions ( $p s>.041)$.

Although the main effect of orthographic similarity was not significant $[F(1,15)<1]$, the two-way interaction between orthographic and phonological similarity $[F(1,15)=12.432$, $\left.M S E=.018, p=.003, \eta^{2}=.008\right]$ was highly significant. Further comparisons revealed that in the Pd conditions, the Od lists (mean $=.89)$ were remembered significantly better than the Os lists $($ mean $=.84)\left[F(1,15)=6.923, M S E=.003, p<.019, \eta^{2}=\right.$ .077], which was consistent with the findings from horizontal characters in Experiment 1. In the Ps conditions, however, the Od lists (mean $=.60$ ) were remembered marginally worse than the Os lists (mean $=.64)[F(1,15)=3.509, M S E=.003, p<$ $\left..081, \eta^{2}=.029\right]$. Visual inspection of the data suggested that the OSE in the Pd conditions might mainly reflect recall accuracy at the first and seventh serial positions, whereas the reversed OSE in the Ps conditions might mainly reflect recall accuracy at the third and fourth serial positions. Planned comparisons confirmed this observation: In the Pd conditions, the OSE was significant at the seventh serial position $[F(1,15)=5.952, M S E=.032, p=$ $\left..028, \eta^{2}=.131\right]$ and marginally significant at the first serial position $\left[F(1,15)=4.459\right.$, MSE $\left.=.053, p=.052, \eta^{2}=.084\right]$. In the Ps conditions, however, a reversed OSE was marginally significant at the third serial position $[F(1,15)=3.947, M S E=$ $\left..049, p=.066, \eta^{2}=.092\right]$ and significant at the fourth serial position $\left[F(1,15)=9.0, M S E=.031, p=.009, \eta^{2}=.161\right]$. Because memory performance was near its lowest at these serial positions, especially when the pronunciations of list characters were highly similar, the marginal advantage enjoyed by the characters in the Os lists might have resulted from the facilitated recognition of Chinese characters with shared radicals.

Because the three-way interaction among orthographic similarity, phonological similarity, and serial position was also significant $\left[F(7,105)=2.447, M S E=.034, p=.023, \eta^{2}=\right.$ $.022]$, a post-hoc analysis was further conducted to verify the contributions of phonological and orthographic codes to serial recall at individual serial positions. Consistent with the planned comparisons above, the results showed that the interaction between orthographic and phonological similarity was significant at the third and forth serial positions $(p s<.027)$, and was marginally significant at the seventh serial position $(p$ $=.084)$. However, it should be noted that these effects were 
Table 2 Characteristics of the materials in Experiment 2

\begin{tabular}{llll}
\hline & PdOd & PdOs & PsOd \\
\hline Mean character frequency & 124 & 94 & 83 \\
Mean stroke number & 13 & 15 & 15 \\
\% occupied by the strokes & 12.61 & 13.52 & 13.37 \\
Mean normalized \% that two characters in a condition overlapped & 26.84 & 30.92 & 14 \\
Mean visual similarity rating $(n=17)$ & 1.97 & 2.45 & 1.91 \\
Mean phonological similarity rating $(n=17)$ & 1.74 & 1.81 & 2.44 \\
\hline
\end{tabular}

For the subjective rating, 1 represents extremely dissimilar, and 6 represents extremely similar

only detected under the threshold without considering multiple comparisons, and they did not survive the Bonferroni correction. Such results suggested that the interaction between the PSE and OSE across serial positions might not differ robustly; hence, no further analysis was conducted.

Direct comparison of experiments $1 a$ and 2 In order to directly examine whether the OSE is reliable and to compare its relative strengths in WM for horizontal and vertical Chinese characters, a 2 (character structure: horizontal vs. vertical) $\times 2$ (phonological similarity: dissimilar vs. similar) $\times 2$ (orthographic similarity: dissimilar vs. similar $) \times 8$ (serial position of the probed character: from 1 to 8 ) mixed ANOVA was performed on the accuracies of the participants' probed serial recall in Experiments 1a and 2. The results showed a significant main effect of character structure $\left[F(1,30)=7.804, M S E=.171, p=.009, \eta^{2}=.027\right]$, indicating that memory performance was better for horizontal characters (.81) than for vertical characters (.74). Also, the ANOVA results revealed strong main effects of phonological similarity $\left[F(1,30)=227.638, M S E=.046, p<.001, \eta^{2}=.181\right]$, orthographic similarity $[F(1,30)=13.376, M S E=.034, p=.001$, $\left.\eta^{2}=.009\right]$, and serial position $[F(7,210)=15.996, M S E=.072$, $\left.p<.001, \eta^{2}=.146\right]$.
The main purpose of the direct comparison of the results from Experiments 1a and 2 was to examine the generalizability and relative strengths of the PSE and OSE in characters with different structures; thus, the interactions between character structure and the other factors are reported below. The interaction between character structure and phonological similarity was significant $[F(1,30)=$ 12.240, MSE $\left.=.046, p=.001, \eta^{2}=.012\right]$, indicating that the PSE was stronger in vertical (.25) than in horizontal (.16) characters. Furthermore, the three-way interaction among character structure, phonological similarity, and serial position $[F(7,210)=2.353, M S E=.039, p=$ $\left..025, \eta^{2}=.013\right]$ was also significant. Post-hoc comparisons revealed that the PSE was significantly greater in vertical than in horizontal characters from the fifth to the seventh serial positions $(p \mathrm{~s}<.036)$, but not at the other serial positions ( $p s>.089)$ (Fig. 4a). The ANOVA results also showed a significant interaction between character structure and orthographic similarity $[F(1,30)=10.446$, $\left.M S E=.034, p=.003, \eta^{2}=.007\right]$, indicating that the OSE was stronger in horizontal (.079) than in vertical (.005) characters (Fig. 4b). No other effects were significant ( $p$ s $>$.128).

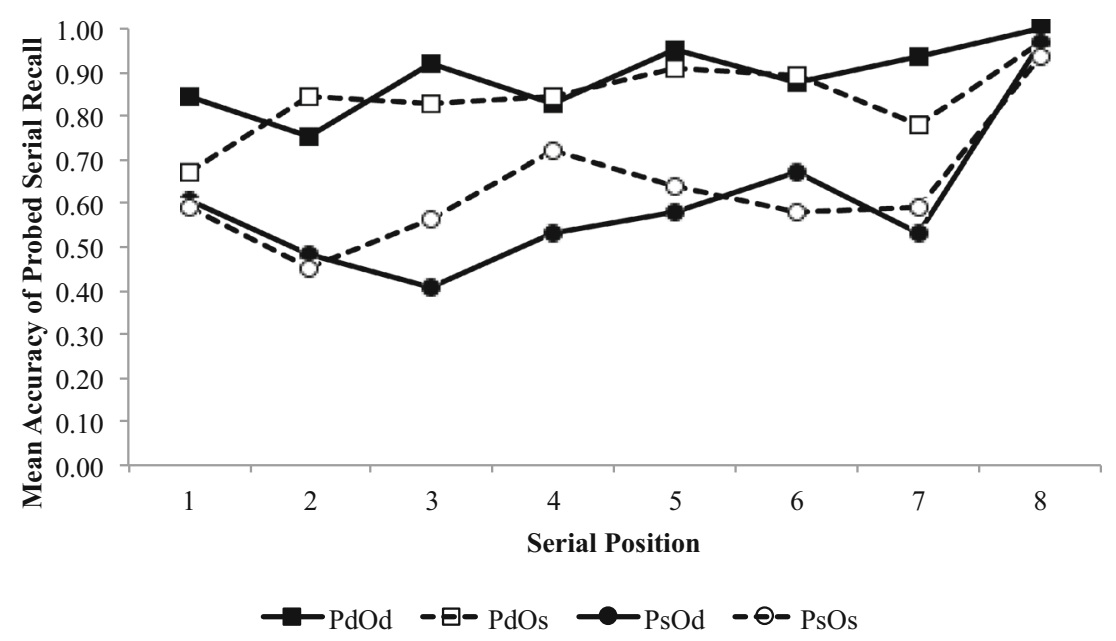

Fig. 3 Mean accuracies of probed serial recall across serial positions in Experiment 2 

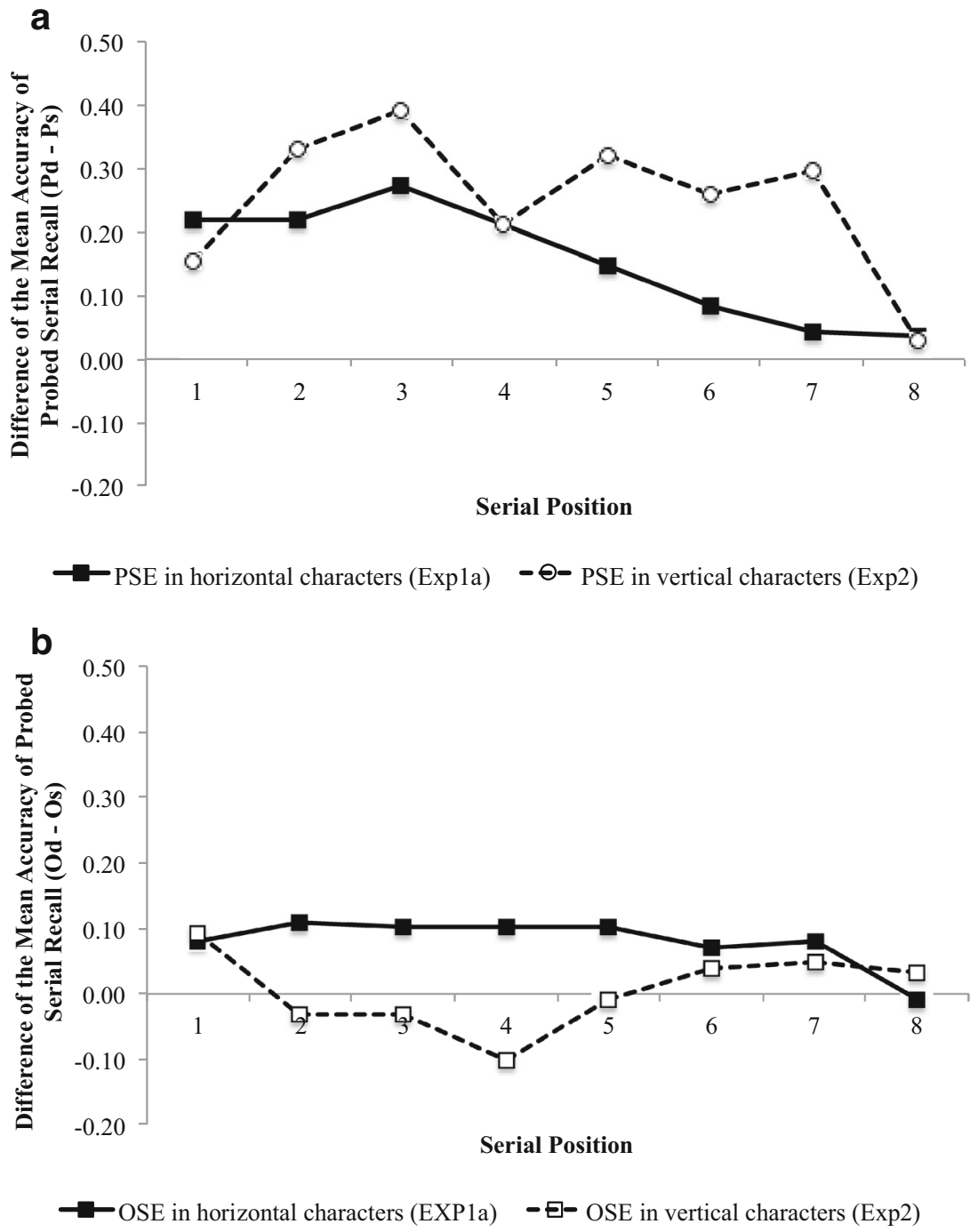

Fig. 4 (a) Effects of phonological similarity in horizontal (Exp. 1a) and vertical (Exp. 2) characters across serial positions. (b) Effects of orthographic similarity in horizontal (Exp. 1a) and vertical (Exp. 2) characters across serial positions

\section{Discussion}

Consistent with the results of Experiment 1 and findings reported in the previous literature (Saito et al., 2008), WM for Chinese vertical characters that are phonologically distinct is supported by orthographic in addition to phonological codes. The direct comparisons between Experiments 1a and 2, firstly, showed that memory performance was better for horizontal than for vertical characters. Secondly, the significant interactions between character structure and the PSE, as well as between character structure and the OSE, indicate that the PSE and OSE were more pronounced in vertical and in horizontal characters, respectively. In Experiment 2, unlike in the results from horizontal characters, however, we did not observe the effect of orthographic similarity when the phonological information of the list items was highly similar. Actually, we observed a weak but reversed OSE, particularly at the serial positions with low memory accuracy. Although it is true that two characters (i.e., 愚/yu2/ and 慈/ci2/) in the PsOd condition also shared a semantic radical (i.e., 心 /xin1/, meaning "heart") at the bottom of the characters, this cannot account for the reversed OSE, because the characters in the PsOs condition shared not only phonetic but also semantic radicals among their characters. The more confusable orthographic codes of the PsOs than of the PsOd characters, as evidenced by the objective index and subjective ratings of visual similarity, should still have resulted in worse memory performance in the former than in the latter condition.

The findings of Experiment 2 ostensibly conflict with previous results that visually dissimilar words were remembered better than visually similar ones, especially when the pronunciations of these words were similar (e.g., Logie et al., 2000; Saito et al., 2008). The effect of shared phonetic radicals improving rather than hindering the WM of phonologically similar characters with a vertical structure might be due to the fact that the orthography of shared phonetic radicals facilitates 
character recognition in LTM (Tsai et al., 2004) but creates memory confusion in WM. When the characters are familiar and common, shared phonetic radicals have little effect on character recognition but affect the memory representations in WM. When the characters are relatively uncommon, on the other hand, the facilitative effect of shared phonetic radicals on accessing the memory items in LTM might contribute more to memory performance.

Indeed, horizontal characters $(\sim 70 \%)$ are more common than vertical characters $(\sim 22 \%)$ in modern Chinese vocabulary (Li \& Chen, 1997), and the stimuli in Experiment 1 were more familiar overall (mean frequency $=201$ per million characters) than those in Experiment 2 (mean frequency $=90$ per million characters). Also, the stroke numbers of the stimuli in Experiment 1 (mean = 11) were fewer than for those in Experiment 2 (mean $=14$ ). Besides, the shared radicals in horizontal characters were always on the right side in Experiment 1, but the shared radicals in vertical characters might appear at the top or the bottom in Experiment 2. All of these factors might have rendered the facilitative effect of shared phonetic radicals in vertical characters on the recognition process to be pronounced, but their inhibitory effect on WM to be weak, which in turn resulted in the reversed OSE, especially at serial positions with poor memory performance.

The potential account of the reversed OSE effect could be that the phonological and orthographic representations in verbal WM correspond to those in LTM, and their availability and usefulness are determined by the characteristics of the corresponding representations in long-term linguistic knowledge. Such reasoning can also explain the stronger PSE observed in vertical than in horizontal characters, as well as the reversed pattern of the OSE. Specifically, the majority of phonograms $(\sim 78 \%)$ in modern Chinese vocabulary have a horizontal structure, and $91 \%$ of these have a phonetic radical on the right side of the character (Hsiao \& Shillcock, 2006). On the other hand, the less common phonograms ( $22 \%$ ) have a vertical structure, and $61 \%$ of them have a phonetic radical at the bottom of the character. As a result, Chinese readers have been reported to be sensitive to the right (phonetic) radicals during character recognition (Wang, 2006). These characteristics of Chinese orthography in LTM might render the orthographic code of the phonetic radical in horizontal characters, especially when it is on the right side, more salient than that in vertical characters in verbal WM, which in turn could result in a greater contribution to recall of horizontal than of vertical characters. Consequently, the OSE resulting from shared phonetic radicals was stronger in horizontal than in vertical phonograms. Following this reasoning, because the phonological and orthographic codes complement each other to support verbal WM, the PSE might have been relatively weak when the OSE was relatively strong in horizontal characters.

It should be noted that other reasons might also contribute to the higher PSE in vertical than in horizontal characters, as well as the higher OSE in horizontal than in vertical characters. In
Experiment 1, the subjective ratings of phonological similarity for the Ps and Pd conditions were 2.33 and 1.97, respectively (Table 1). In Experiment 2, the same indices were 2.52 and 1.77 for the Ps and Pd conditions, respectively (Table 2). Because the manipulation strength of phonological similarity in Experiment 1 (0.36) was weaker than that in Experiment $2(0.75)[F(1,33)=$ $\left.38.38, M S E=.017, p<.001, \eta^{2}=.037\right]$, the observed strength of the PSE might reflect such a difference in the stimuli between Experiments 1 and 2. Similarly, in Experiment 1 the objective indices of visual similarity for the Os and Od conditions were $33.06 \%$ and $25.26 \%$, respectively. In Experiment 2, the same indices were $30.20 \%$ and $27.29 \%$ for the Os and Od conditions, respectively. Direct comparison of these indices showed that the manipulation strength of visual similarity in Experiment 1 (7.80 \%) was stronger than that in Experiment 2 (2.91\%) $[F(1$, $\left.28)=5.83, M S E=.0009, p=.023, \eta^{2}=.17\right]$. The subjective ratings of visual similarity also reflected the same pattern: the subjective visual similarity of the stimuli in Experiment 1 (Os conditions: 2.94, Od conditions: 1.81, difference of 1.13) was stronger than that in Experiment 2 (Os conditions: 2.43, Od conditions: 1.94 , difference of 0.49$)[F(1,33)=48.62, M S E=$ $\left..037, p<.001, \eta^{2}=.06\right]$. That is, both the objective indices and the rating scores were in parallel with the observed strengths of the OSEs between Experiments 1 and 2. However, we would point out that because the subjective ratings of the stimuli of Experiments 1 and 2 were obtained from two groups of participants with two sets of stimuli, these values might not be directly comparable between the two experiments, and should be interpreted with caution.

\section{General discussion}

In the present study, we investigated the contributions of the phonological and orthographic representations of Chinese characters to WM performance. In the experiments reported here, the classic effects of phonological similarity, articulatory suppression, and serial position were consistently observed, which replicated numerous studies in the literature. Critically, independent manipulation of orthographic similarity among the experimental stimuli was mainly achieved by including characters with shared phonetic radicals, which have been shown to bear functional importance in recognizing Chinese characters (Hung et al., 2014; Lee et al., 2005). It should also be noted that the characters in the Os conditions also shared more semantic radicals than did those in the Od conditions. The OSEs of short-term retention of these materials were reliably observed in horizontal and vertical Chinese characters (Exps. 1 and 2, respectively), especially in the lists whose characters all had distinct pronunciations. These results provide strong evidence for the indispensable contribution of orthographic representations to the short-term retention of Chinese characters, even when participants could fully rely on phonological representations to achieve the memory task. In other words, Chinese 
readers rely on both pronunciations and word forms, which are largely nonredundant linguistic information of Chinese characters, to actively retain verbal materials in WM.

To achieve independent manipulations of phonological and orthographic similarity among the list items, the Chinese characters in the PdOs condition had phonetic radicals with low phonetic consistency; that is, the phonetic radicals appeared in characters with different pronunciations. Indeed, in Experiment 1 the mean phonetic consistency of the PdOs characters (.27) was much lower than that of the PdOd characters (.49) with a horizontal structure. However, the mean phonetic consistencies were well matched between these two conditions for Chinese characters with a vertical structure (PdOs: .37, PdOd: .38) in Experiment 2. Because the WM performance clearly demonstrated the OSE when the character pronunciations were all different in both Experiments 1 and 2, the difference in the phonetic consistency of the phonetic radicals cannot fully account for the worse memory of characters sharing the same (relatively inconsistent) phonetic radicals. Rather, we attribute the OSE to the orthographic representations of phonetic radicals in WM, which were more confusable in the Os than in the Od condition.

To account for the findings that readers of both alphabetic and logographic languages remembered visually dissimilar words better than visually similar ones, especially when the sounds of these words were similar (e.g., Logie et al., 2000; Saito et al., 2008), it has been assumed that the visuo-spatial sketchpad in the WM model is available to support the retention of verbal materials, especially when the phonological loop is not optimal for memory performance (Logie, 1986, 1995; Logie, Brockmole, \& Jaswal, 2011; Logie, Zucco, \& Baddeley, 1990). In other words, the involvement of visual codes in verbal WM is spontaneous and optional, whenever it can be helpful. The reliable OSE observed in both horizontal and vertical characters whose pronunciations were dissimilar further extends the previous findings in showing that the contribution of orthographic codes to the retention of Chinese characters is not supplementary to the contribution of phonological codes. Consistent with the results of Saito et al., the reliance on word forms to retain the materials in a deep orthography is automatic and indispensible.

In addition to demonstrating the phonological and orthographic components of the WM of Chinese characters, the present findings showed that the relative contributions of these components respect the characteristics of the corresponding phonological and orthographic representations in LTM. Specifically, the OSE arising mainly from the shared phonetic radicals at the right side of horizontal characters was greater than that arising from shared phonetic radicals at either the top or the bottom of vertical characters. One possible account for such finding is that the manipulation of visual similarity among the horizontal characters in Experiment 1 was indeed stronger than that among the vertical characters in Experiment 2. This result is also consistent with the finding that Chinese readers distribute their attention to the right side of characters (Wang, 2006), due to the presence of more horizontal than vertical phonograms in modern Chinese vocabulary, and to the uneven distributions of the locations of the phonetic radicals within phonograms with different structures. The complementary PSE, on the other hand, showed the opposite pattern of strength in characters with different structures. In addition to reflecting the stronger manipulation of phonological similarity among vertical characters in Experiment 2 than among horizontal characters in Experiment 1, these results are also compatible with the idea that the reliance on phonological and orthographic codes might depend on the characteristics of Chinese orthography in LTM.

Although the VSE reported in the previous literature has been assumed to reflect the involvement of the visuo-spatial sketchpad in the WM model (Logie et al., 2000; Saito et al., 2008), the OSE observed in the present study might not result from the same mechanism, because this capacity is conceptualized as being a nonlinguistic buffer that does not connect to the language representations in long-term knowledge (Logie et al., 1990). Instead, the present findings are consistent with the theories of multiple components of verbal WM (e.g., Martin \& Romani, 1994; Martin et al., 1994). According to this approach, LTM and WM correspond to each other closely and have parallel representations. Following this reasoning, verbal materials are retained in semantic, syntactic, and orthographic representations, in additional to phonological ones. For example, previous studies based on alphabetic languages have identified effects of the word frequency (Hulme et al., 1991; Hulme et al., 1997), concreteness (Acheson et al., 2010), and pleasantness (Monnier \& Syssau, 2008) of list items on verbal WM. The present findings not only provide evidence for the orthographic component of verbal WM, but also highlight the close relationship between representations in WM and LTM.

It should be noted, however, that the OSE observed in the present study did not reflect a contribution of orthographic representations in LTM to WM performance, since a close set of stimuli was employed to minimize the influence of long-term linguistic knowledge (Monnier \& Syssau, 2008). Besides, the accuracy of probed serial recall is heavily determined by the order information stored in WM, rather than the item information that might be supported by LTM (Poirier \& Saint-Aubin, 1996). Moreover, the repetition of phonetic radicals facilitates the recognition of Chinese characters in LTM (e.g., Hung et al., 2014; Tan et al., 1998), whereas it creates memory confusion in verbal WM. Therefore, the worse recall of orthographically similar than of dissimilar characters indeed indicated the involvement of orthographic codes in WM. The advantage of sharing phonetic radicals for recognizing characters in LTM was only hinted at when memory performance was poor (i.e., to remember vertical characters that were phonologically similar at the third and fourth serial positions). 
In conclusion, the findings from the two experiments in the present study provide strong evidence for the contributions of both phonology and orthography to verbal WM of Chinese characters. Critically, the support from character forms, albeit smaller than the dominant support from character pronunciations, is indispensable rather than supplementary. Furthermore, the relative strengths of the PSE and the OSE in horizontal and vertical characters suggest that the usefulness of phonological and orthographic codes in verbal WM depends on the characteristics of their corresponding representations in LTM. These results also indicate the importance of sublexical units embedded in Chinese orthography to verbal WM. All together, the present findings demonstrate that the linguistic knowledge of a specific language not only determines the processing mechanisms of that language, but also delineates the organization of verbal WM for that language.

Author note This research was supported by grants from the National Science Council (Grant Nos. NSC 98-2410-H-008-012, NSC 100-2911I-008-505) and from Academia Sinica (Grant No. AS-102-TP-C06) in Taiwan.

\section{Appendix A}

Table 3 Stimuli used in Experiment $1 \mathrm{a}$ and $1 \mathrm{~b}$

\begin{tabular}{|c|c|c|c|c|c|}
\hline Condition & Orthography & Phonology & Meaning & Stroke number & $\begin{array}{l}\text { Character frequency } \\
\text { (per million characters) }\end{array}$ \\
\hline \multirow[t]{8}{*}{ PdOd } & 秋 & qiu1 & autumn & 9 & 89 \\
\hline & 錻 & gai4 & calcium & 12 & 12 \\
\hline & 預 & yu4 & in advance & 13 & 396 \\
\hline & 瓶 & ping2 & bottle & 11 & 61 \\
\hline & 隊 & dui4 & team & 12 & 496 \\
\hline & 般 & ban1 & a kind & 10 & 392 \\
\hline & 貼 & tiel & paste & 12 & 78 \\
\hline & 弱 & ruo4 & weak & 10 & 107 \\
\hline \multirow[t]{8}{*}{ PdOs } & 洛 & luo4 & (a river's name) & 9 & 30 \\
\hline & 格 & ge2 & square & 10 & 516 \\
\hline & 海 & hai3 & ocean & 10 & 501 \\
\hline & 梅 & mei2 & plum & 11 & 80 \\
\hline & 愧 & kui4 & ashamed & 13 & 16 \\
\hline & 槐 & huai2 & Pagoda tree & 14 & 1 \\
\hline & 泊 & bo 2 & berth & 8 & 16 \\
\hline & 怕 & pa4 & fear & 8 & 248 \\
\hline \multirow[t]{8}{*}{ PsOd } & 詞 & ci2 & words & 12 & 383 \\
\hline & 磁 & ci2 & magnet & 14 & 44 \\
\hline & 愺 & ren4 & tough & 12 & 7 \\
\hline & 任 & ren4 & assign & 6 & 629 \\
\hline & 租 & zu1 & rent & 10 & 94 \\
\hline & 㨋 & zhu1 & pig & 15 & 65 \\
\hline & 殿 & dian4 & palace & 13 & 30 \\
\hline & 建 & jian4 & establish & 9 & 629 \\
\hline \multirow[t]{8}{*}{ PsOs } & 惟 & wei2 & only & 11 & 264 \\
\hline & 維 & wei2 & maintain & 14 & 35 \\
\hline & 惆 & wang3 & desolate & 11 & 568 \\
\hline & 網 & wang3 & net & 14 & 4 \\
\hline & 校 & xiao4 & school & 10 & 629 \\
\hline & 絞 & jiao3 & twist & 12 & 7 \\
\hline & 枕 & zhen 3 & pillow & 8 & 13 \\
\hline & 沈 & chen 2 & sink & 7 & 7 \\
\hline
\end{tabular}

All of the characters were sampled from the Academia Sinica Balanced Corpus of Modern Chinese (www.sinica.edu.tw/SinicaCorpus/) 


\section{Appendix B}

Table 4 Stimuli used in Experiment 2

\begin{tabular}{|c|c|c|c|c|c|}
\hline Condition & Orthography & Phonology & Meaning & Stroke Number & $\begin{array}{l}\text { Character Frequency } \\
\text { (per million characters) }\end{array}$ \\
\hline \multirow[t]{8}{*}{ PdOd } & 筒 & tong3 & tube & 12 & 24 \\
\hline & 尊 & zun1 & respect & 12 & 140 \\
\hline & 量 & yun1 & dizzy & 13 & 13 \\
\hline & 冀 & $\mathrm{ji} 4$ & aim & 16 & 7 \\
\hline & 察 & cha2 & inspect & 14 & 200 \\
\hline & 興 & xing1 & cheerful & 16 & 471 \\
\hline & 辜 & gu1 & crime & 12 & 14 \\
\hline & 紫 & zi3 & purple & 12 & 26 \\
\hline \multirow[t]{8}{*}{ PdOs } & 熱 & $\operatorname{dian} 4$ & cushion & 14 & 14 \\
\hline & 摰 & zhi4 & sincere & 15 & 6 \\
\hline & 疊 & dei2 & stack & 22 & 25 \\
\hline & 壘 & lei3 & base & 18 & 25 \\
\hline & 萬 & wan4 & ten thousand & 13 & 620 \\
\hline & 寓 & yu4 & residence & 12 & 23 \\
\hline & 豎 & shu4 & upright & 15 & 13 \\
\hline & 登 & deng1 & ascend & 12 & 148 \\
\hline \multirow[t]{8}{*}{ PsOd } & 勢 & shi4 & situation & 13 & 386 \\
\hline & 誓 & shi4 & swear & 14 & 13 \\
\hline & 鶯 & ying1 & warbler & 21 & 11 \\
\hline & 膺 & ying1 & heart & 17 & 4 \\
\hline & 愚 & yu2 & stupid & 13 & 20 \\
\hline & 輿 & yu3 & carriage & 17 & 13 \\
\hline & 慈 & ci2 & merciful & 11 & 66 \\
\hline & 瓷 & ci2 & porcelain & 13 & 64 \\
\hline \multirow[t]{8}{*}{ PsOs } & 翠 & cui4 & emerald & 12 & 26 \\
\hline & 萃 & cui4 & assemble & 14 & 3 \\
\hline & 藍 & $\operatorname{lan} 2$ & blue & 20 & 63 \\
\hline & 籃 & $\operatorname{lan} 2$ & basket & 18 & 83 \\
\hline & 努 & nu3 & strive & 7 & 159 \\
\hline & 怒 & nu4 & anger & 9 & 54 \\
\hline & 幕 & mu4 & curtain & 14 & 109 \\
\hline & 慕 & mu4 & admire & 14 & 34 \\
\hline
\end{tabular}

\section{References}

Acheson, D. J., Postle, B. R., \& MacDonald, M. C. (2010). The interaction of concreteness and phonological similarity in verbal working memory. Journal of Experimental Psychology: Learning, Memory, and Cognition, 36, 17-36. doi:10.1037/ a0017679

Baddeley, A. (1966a). The influence of acoustic and semantic similarity on long-term memory for word sequences. Quarterly Journal of Experimental Psychology, 18, 302-309. doi:10.1080/ 14640746608400047

Baddeley, A. (1966b). Short-term memory for word sequences as a function of acoustic, semantic and formal similarity. Quarterly
Journal of Experimental Psychology, 18, 362-365. doi:10.1080/ 14640746608400055

Baddeley, A. (1986). Working memory. Oxford, UK: Oxford University Press.

Baddeley, A. (2000). The episodic buffer: A new component of working memory? Trends in Cognitive Sciences, 4, 417-423. doi:10.1016/ S1364-6613(00)01538-2

Baddeley, A. D., \& Hitch, G. J. (1974). Working memory. In G. H. Brown (Ed.), The psychology of learning and motivation (Vol. 8, pp. 47-89). New York, NY: Academic Press. doi:10.1016/s0079-7421(08)60452-1

Baddeley, A., Lewis, V., \& Vallar, G. (1984). Exploring the articulatory loop. Quarterly Journal of Experimental Psychology, 36, 233-252. doi:10.1080/14640748408402157 
Baddeley, A. D., Thomson, N., \& Buchanan, M. (1975). Word length and structure of short-term-memory. Journal of Verbal Learning and Verbal Behavior, 14, 575-589. doi:10.1016/S0022-5371(75) 80045-4

Besner, D., \& Davelaar, E. (1982). Basic processes in reading: Two phonological codes. Canadian Journal of Psychology, 36, 701711. doi:10.1037/h0080665

Brener, R. (1940). An experimental investigation of memory span. Journal of Experimental Psychology, 26, 467-482. doi:10.1037/ h0061096

Caza, N., \& Belleville, S. (1999). Semantic contribution to immediate serial recall using an unlimited set of items: Evidence for a multilevel capacity view of short-term memory. International Journal of Psychology, 34, 334-338. doi:10.1080/002075999399657

Conrad, R., \& Hull, A. J. (1964). Information, acoustic confusion and memory span. British Journal of Psychology, 55, 429-432. doi:10. 1016/S0022-5371(75)80045-4

Crowder, R. G. (1976). The locus of the lexicality effect in short-term memory for phonologically identical lists. Bulletin of the Psychonomic Society, 7, 361-363. doi:10.3758/BF03337216

Ding, G. S., Peng, D. L., \& Taft, M. (2004). The nature of the mental representation of radicals in Chinese: A priming study. Journal of Experimental Psychology: Learning, Memory, and Cognition, 30, 530-539. doi:10.1037/0278-7393.30.2.530

Feldman, L. B., \& Siok, W. W. T. (1997). The role of component function in visual recognition of Chinese characters. Journal of Experimental Psychology: Learning, Memory, and Cognition, 23, 776-781. doi: 10.1037/0278-7393.23.3.776

Feldman, L. B., \& Siok, W. W. T. (1999). Semantic radicals contribute to the visual identification of Chinese characters. Journal of Memory and Language, 40, 559-576. doi:10.1006/jmla.1998.2629

Freedman, M. L., \& Martin, R. C. (2001). Dissociable components of short-term memory and their relation to long-term learning. Cognitive Neuropsychology, 18, 193-226. doi:10.1080/ 02643290042000080

Frost, R., Katz, L., \& Bentin, S. (1987). Strategies for visual word recognition and orthographical depth: A multilingual comparison. Journal of Experimental Psychology: Human Perception and Performance, 13, 104-115. doi:10.1037/0096-1523.13.1.104

Fürstenberg, A., Rummer, R., \& Schweppe, J. (2013). Does visuo-spatial working memory generally contribute to immediate serial letter recall? Memory, 21, 722-731. doi:10.1080/09658211.2012.753462

Hitch, G. J., Woodin, M. E., \& Baker, S. (1989). Visual and phonological components of working memory in children. Memory \& Cognition, 17, 175-185. doi:10.3758/BF03197067

Hsiao, J. H., \& Shillcock, R. (2006). Analysis of a Chinese phonetic compound database: Implications for orthographic processing. Journal of Psycholinguistic Research, 35, 405-426. doi:10.1007/ s10936-006-9022-y

Huang, C.-R., \& Chen, K.-J. (1998). Academia Sinica balanced corpus. Taipei, Taiwan: Chinese Knowledge and Information Processing Group, Academia Sinica.

Hue, C.-W., \& Erickson, J. R. (1988). Short-term memory for Chinese characters and radicals. Memory \& Cogmtion, 16, 196. doi:10.3758/ $\mathrm{BF} 03197752$

Hulme, C., Maughan, S., \& Brown, G. D. A. (1991). Memory for familiar and unfamiliar words: Evidence for a long-term memory contribution to short-term memory span. Journal of Memory and Language, 30, 685-701. doi:10.1016/0749-596X(91)90032-F

Hulme, C., Roodenrys, S., Schweickert, R., Brown, G. D. A., Martin, S., \& Stuart, G. (1997). Word-frequency effects on short-term memory tasks: Evidence for a redintegration process in immediate serial recall. Journal of Experimental Psychology: Learning, Memory, and Cognition, 23, 1217-1232. doi:10.1037/0278-7393.23.5.1217

Hung, Y., Hung, D. L., Tzeng, O. J. L., \& Wu, D. H. (2014). Tracking the temporal dynamics of the processing of phonetic and semantic radicals in Chinese character recognition by MEG. Journal of Neurolinguistics, 29, 42-65. doi:10.1016/j.jneuroling.2013.12.003

Lee, C. Y., Tsai, J. L., Kuo, W. J., Yeh, T. C., Wu, Y. T., Ho, L. T., ... Hsieh, J. C. (2004). Neuronal correlates of consistency and frequency effects on Chinese character naming: an event-related MRI study. Neuroimage, 23(4), 1235-1245. doi:10.1016/j.neuroimage.2004. 07.064

Lee, C. Y., Tsai, J. L., Su, E. C. I., Tzeng, O. J. L., \& Hung, D. L. (2005). Consistency, regularity, and frequency effects in naming Chinese characters. Language and Linguistics, 6, 75-107. Retrieved from www.ling.sinica.edu.tw/files/publication/j2005_1_03 9113.pdf

Li, H., \& Chen, C.-H. (1997). Processing of radicals in Chinese character recognition. In H.-C. Chen (Ed.), Cognitive processing of Chinese and related Asian languages (pp. 141-160). Hong Kong: Chinese University Press.

Logie, R. H. (1986). Visuo-spatial processing in working memory. Quarterly Journal of Experimental Psychology Section A, 38, 229-247. doi:10.1080/14640748608401596

Logie, R. H. (1995). Visuo-spatial working memory. Hove, UK: Psychology Press.

Logie, R. H., Brockmole, J. R., \& Jaswal, S. (2011). Feature binding in visual short-term memory is unaffected by task-irrelevant changes of location, shape, and color. Memory \& Cognition, 39, 24-36. doi: 10.3758/s13421-010-0001-z

Logie, R. H., Della Sala, S., Wynn, V., \& Baddeley, A. (2000). Visual similarity effects in immediate verbal serial recall. Quarterly Journal of Experimental Psychology, 53A, 626-646. doi:10.1080/ 027249800410463

Logie, R. H., \& Marchetti, C. (1991). Visuo-spatial working memory: Visual, spatial or central executive? Advances in Psychology, 80, 105-115. doi:10.1016/S0166-4115(08)60507-5

Logie, R. H., Zucco, G. M., \& Baddeley, A. (1990). Interference with visual short-term memory. Acta Psychologica, 75, 55-74. doi:10. 1016/0001-6918(90)90066-O

Martin, R. C., \& Romani, C. (1994). Verbal working memory and sentence comprehension: A multiple-components view. Neuropsychology, 8, 506-523. doi:10.1037/0894-4105.8.4.506

Martin, R. C., Shelton, J. R., \& Yaffee, L. S. (1994). Language processing and working memory: Neuropsychological evidence for separate phonological and semantic capacities. Journal of Memory and Language, 33, 83-111. doi:10.1006/jmla.1994.1005

Martin, R. C., Wu, D. H., Freedman, M. L., Jackson, E. F., \& Lesch, M. (2003). An event-related fMRI investigation of phonological versus semantic short-term memory. Journal of Neurolinguistics, 16, 341360. doi:10.1016/S0911-6044(03)00025-3

Monnier, C., \& Syssau, A. (2008). Semantic contribution to verbal shortterm memory: Are pleasant words easier to remember than neutral words in serial recall and serial recognition? Memory \& Cognition, 36, 35-42. doi:10.3758/MC.36.1.35

Mou, L. C., \& Anderson, N. S. (1981). Graphemic and phonemic codings of Chinese characters in short-term retention. Bulletin of the Psychonomic Society, 17, 255-258. doi:10.3758/BF03333732

Murray, D. J. (1968). Articulation and acoustic confusability in short-term memory. Journal of Experimental Psychology, 78, 676-684. doi:10. 1037/h0026641

Poirier, M., \& Saint-Aubin, J. (1996). Immediate serial recall, word frequency, item identity and item position. Canadian Journal of Experimental Psychology, 50, 408. doi:10.1037/1196-1961.50.4.408

Poirier, M., Saint-Aubin, J., Musselwhite, K., Mohanadas, T., \& Mahammed, G. (2007). Visual similarity effects on short-term memory for order: The case of verbally labeled pictorial stimuli. Memory \& Cognition, 35, 711-723. doi:10.3758/BF03193309

Romani, C., McAlpine, S., \& Martin, R. C. (2008). Concreteness effects in different tasks: Implications for models of short-term memory. Quarterly Journal of Experimental Psychology, 61, 292-323. doi: 10.1080/17470210601147747 
Roodenrys, S., Lethbridge, A., Hinton, M., Nimmo, L. M., \& Hulme, C. (2002). Word-frequency and phonological-neighborhood effects on verbal short-term memory. Journal of Experimental Psychology: Learning, Memory, and Cognition, 28, 1019-1034. doi:10.1037/ 0278-7393.28.6.1019

Saito, S., Logie, R. H., Morita, A., \& Law, A. (2008). Visual and phonological similarity effects in verbal immediate serial recall: A test with kanji materials. Journal of Memory and Language, 59, 117. doi:10.1016/j.jml.2008.01.004

Shivde, G., \& Anderson, M. C. (2011). On the existence of semantic working memory: Evidence for direct semantic maintenance. Journal of Experimental Psychology: Learning, Memory, and Cognition, 37, 1342-1370. doi:10.1037/a0024832

Shivde, G., \& Thompson-Schill, S. L. (2004). Dissociating semantic and phonological maintenance using fMRI. Cognitive, Affective, \& Behavioral Neuroscience, 4, 10-19. doi:10.3758/ CABN.4.1.10

Taft, M., \& Zhu, X. (1997). Submorphemic processing in reading Chinese. Journal of Experimental Psychology: Learning, Memory, and Cognition, 23, 761-775. doi:10.1037/0278-7393. 23.3.761
Taft, M., Zhu, X., \& Peng, D. (1999). Positional specificity of radicals in Chinese character recognition. Journal of Memory and Language, 40, 498-519. doi:10.1006/jmla.1998.2625

Tan, L., \& Perfetti, C. A. (1998). Phonological codes as early sources of constraint in Chinese word identification: A review of current discoveries and theoretical accounts. Reading and Writing, 10(3-5), 165-200. doi:10.1023/A:1008086231343

Tsai, J. L., Lee, C. Y., Tzeng, O. J. L., Hung, D. L., \& Yen, N. S. (2004). Use of phonological codes for Chinese characters: Evidence from processing of parafoveal preview when reading sentences. Brain and Language, 91, 235-244. doi:10.1016/j.bandl.2004.02.005

Walker, I., \& Hulme, C. (1999). Concrete words are easier to recall than abstract words: Evidence for a semantic contribution to short-term serial recall. Journal of Experimental Psychology: Learning, Memory, and Cognition, 25, 1256-1271. doi:10.1037/0278-7393.25.5.1256

Wang, M. (2006). Examining the bias for orthographic components using an apparent motion detection task. Psychologia, 49, 193-213. doi: 10.2117 psysoc. 2006.193

Warrington, E., \& Shallice, T. (1972). Neuropsychological evidence of visual storage in short-term memory tasks. Quarterly Journal of Experimental Psychology, 24, 30-40. doi:10.1080/14640747208400265 